\title{
Effect of calcium hydroxide-propolis combination on the number of fibroblast cells and angiogenesis in Wistar rats pulp
}

\author{
Nirawati Pribadi, Ira Widjiastuti and Agata Nadia \\ Departemen of Conservative Dentistry, \\ Faculty of Dental Medicine, Universitas Airlangga, \\ Surabaya, Indonesia
}

\begin{abstract}
Background: The vitality of the pulp must be protected because the pulp contains fibers, cells, and various structures. Pulp vitality can be maintained by pulp capping to stimulate the formation of reparative dentin. The material commonly used for pulp capping is calcium hydroxide. Calcium hydroxide has the disadvantage of causing inflammation and necrosis of the pulp surface. To compensate that, propolis is added because it has the ability as an anti-inflammatory. Purpose: To analyze the increase in the number of fibroblast cells and angiogenesis in the pulp after the application of combination of Calcium hydroxide-propolis compared to the application of Calcium hydroxide. Methods: This study used 30 samples of wistar rats which were preparated until perforation and then divided into 3 groups. The first group continued with filling with cention, the second group continued with application of calcium hydroxide and filled with cention, and the third group continued with the application of combination of calcium hydroxide and propolis and then being filled with cention. fibroblast cells and angiogenesis was calculated histopathologically by using compound light microscope on the 7th day with 400x magnification. Results: Based on the results of the study found a significant difference between the calcium hydroxide group and the calcium hydroxide-propolis group. Increased numbers of fibroblasts and angiogenesis indicate a faster inflammatory process that affects the acceleration of wound healing Conclusion: More number of fibroblasts and angiognesis cells found in the pulp after the application of a combination of Calcium hydroxide-propolis compared to the application of Calcium hydroxide
\end{abstract}

Keywords: Calcium Hydroxide; propolis; fibroblast; angiogenesis

Correspondence: Ira Widjiastuti, Departemen of Conservative Dentistry, Faculty of Dental Medicine, Universitas Airlangga, Jl. Mayjen Prof. Dr. Moestopo No.47, Surabaya, Indonesia,60132.Email: ira-w@fkg.unair.ac.id

\section{INTRODUCTION}

The dental health of the Indonesian people needs to be maitained. Dental and oral diseases are in the top ten most diseases spread in various regions ${ }^{1}$. Dental and oral health is often not a priority for many people as evidenced by the percentage of population who have dental and mouth problems according to Riskesdas in 2013 and 2018 increased from $25.9 \%$ to $57.6 \%$. According to Research Health Basic (RISKESDAS) year 2018, the prevalence of active caries (age above 12 years) amounted to $65.5 \%$ and free of caries at $34.5 \%$. Caries are not carried out the treatment will have an impact on the health of the pulp. Pulp vitality must be protected because the pulp contains fibers, cells and various structures such as blood vessels, sensory nerves, and lymphatic tissue ${ }^{2}$.

The vitality of the pulp can be maintained by pulp capping. Direct pulp capping is one of the most widely used pulp capping methods to cover the exposed dental pulp due to mechanical activity in the form of iatrogenic injury with adhesive resin material. Direct pulp capping material can stimulate the formation of reparative dentin ${ }^{3}$.

Calcium hydroxide is a material that has been widely used since the 1920s until now. Not only is it used as a medicament and root canal sealer, but it is also used as a pulp capping material. Calcium hydroxide can kill microorganisms because it has a high $\mathrm{pH}$. In addition, this condition can also stimulate the formation of fibroblasts. This is because calcium hydroxide can stimulate the growth of tertiary dentin for remineralization.

Calcium hydroxide has deficiencies that cause inflammation and necrosis of the surface of the pulp after the pulp capping, has high solubility, may undergo degradation, forming a brittle dentin bridge, and has low mechanical barriers and may be able to cause microfiltration and causing failure of treatment ${ }^{4}$.

The problem of unmaintained inflammation will cause a chronic inflammation in tissue pulp thus causing the 
degeneration response or necrosis of the pulp. To prevent complications, antiinflammatory material has been used in the treatment of lesions of profunda caries or perforated pulp on permanent teeth with closed apex, one of which is propolis.

Propolis is a resin material collected by honey bees from various plants that have been used as anti-inflammatory drugs. This happens because propolis contains flavonoids and Caffeic Acid ${ }^{3.5}$. Propolis has an anti-inflammatory effect by reducing vascular permeability thereby reducing the process of leukocytosis to the lesion area ${ }^{6}$.

Based on the background behind it, more research is needed on the effectiveness of the administration of a combination of calcium hydroxide and propolis as an antiinflammatory in terms of the number of cell fibroblasts and angiogenesis in the tissue of the pulp of Wistar rat's teeth.

\section{MATERIALS AND METHODS}

Ethical eligibility was approved by the Ethics Committee of the Faculty of Dentistry, Airlangga University (Number: 729 / HRECC.FODM / X / 2019). This research is a laboratory experimental study with a posttest only control group using 30 male Wistar (Rattus norvegicus) experimental animals with a healthy age of about 3 months and weighing 200-250 grams. Samples were divided equally into three groups: After the first molar teeth were perforated, the first group continued with cention filling, the second group continued with application of calcium hydroxide and filled with cention, and the third group continued with the application of a combination of calcium hydroxide and propolis then being filled with cention.

Mice that have been grouped performed anesthesia in intramuscular with ketamine $10 \%$ and xylazine $\mathrm{HCl} 0.4 \%$ . Preparation on the surface of the occlusal of the first molar tooth using a round bur (diameter $0.8 \mathrm{~mm}$ ) with a low speed handpiece with the depth of the preparation as deep as the head bur (1.5 to $2 \mathrm{~mm})$. The cavity is perforated using a straight sonde $(0,46 \mathrm{~mm}$ diameter $)$ with a mild pressure, until there is a red spot which is known by using a paper point . After perforation, do irrigation with a solution of sterile saline ( sodium chloride $0.9 \%$ ) in the cavity and dried by using a cotton pellet. Bleeding stopped by sterile paper points. Then do the provision of treatment in accordance groups, control group directly filled with cention, group I was given a combination of calcium hidroxide- distilled

Table 1. Sample number, mean, and standard deviation of the number of Fibroblast cells

\begin{tabular}{lccc}
\hline \multirow{2}{*}{ Treatment Group } & \multirow{2}{*}{ N } & \multicolumn{2}{c}{ Fibroblast } \\
\cline { 3 - 4 } & & Mean & SD \\
\hline Control & 10 & 7.7000 & 0.94868 \\
$\mathrm{Ca}(\mathrm{OH})_{2}$ & 10 & 9.1000 & 0.73786 \\
$\mathrm{Ca}(\mathrm{OH})_{2}+$ Propolis & 10 & 10.4000 & 0.96609 \\
\hline
\end{tabular}

water 1: 1 then filled with cention, and group II was given a combination of calcium hidroxide- propolis 1 : 1.5 and then filled with cention. Material applications in cavities is using a Half Moon sonde .

After the 7th day the rats were necropsed, and then the right upper jaw is cut. Histological preparations were made by staining HE (Haematoxylin Eosin). Observation and calculation of the number of fibroblast cells and angiogenesis in the preparation was carried out using a Nikon Eclipse E200 light microscope with 400x magnification with 8 visual field boxes.

Data were analyzed by using IBM SPSS 20 statistical software. The normality test uses the Shapiro-Wilk test , then the homogeneity test with the Levene test . To determine the mean difference between the groups in the factors use one way Anova test if the data are normaly distributed and use Kruskal-Wallis test when data are not normally distributed, then continued to the Post Hoc Test ( Tukey HSD) to see the comparison between samples .

\section{RESULTS}

Based on anatomic histopathological (HPA) observations, the calculation of the number of fibroblast cells was obtained with the mean and standard deviation of the control group, the first treatment by giving $\mathrm{Ca}(\mathrm{OH})_{2}$-aquadest, and the second treatment by administering $\mathrm{Ca}(\mathrm{OH})_{2}$-propolis in Table 1.

It can be seen through Table 1 the average number of fibroblast cells of the three treatment groups. In the control group, the $\mathrm{Ca}(\mathrm{OH})_{2}$ group and the $\mathrm{Ca}(\mathrm{OH})_{2}+$ Propolis group, all three experienced an increase. Histopathological picture of the anatomy (HPA) of fibroblasts with 400x magnification in the pulp perforation of wistar rats can be seen in Figure 1.

In the normality test it is found that the data is not normally distributed, so the non-parametric test is done using the Kruskal-Wallis test in each group to find out whether there is a significant difference between the treatment groups. Kruskal-Wallis test results obtained a significance value of 0,000 which indicates there are significant differences between treatment groups

Because the Kruskal-Wallis test results obtained significant differences, the next test is the Post Hoc Test using Tukey HSD which aims to find out which groups have significant differences. Table 2 shows that there were

Tabel 2. Fibroblast Tukey HSD Multiple Comparisons Test

\begin{tabular}{|c|c|c|c|}
\hline $\begin{array}{l}\text { Treatment } \\
\text { Group }\end{array}$ & Control & $\mathrm{Ca}(\mathrm{OH})_{2}$ & $\begin{array}{c}\mathrm{Ca}(\mathrm{OH})_{2}+ \\
\text { Propolis }\end{array}$ \\
\hline Control & & $0.004^{*}$ & $0.000^{*}$ \\
\hline $\mathrm{Ca}(\mathrm{OH})_{2}$ & & & $0.008 *$ \\
\hline $\begin{array}{l}\mathrm{Ca}(\mathrm{OH})_{2}+ \\
\text { Propolis }\end{array}$ & & & \\
\hline
\end{tabular}


Tabel 3. Sample number, mean, and standard deviation of the number of Angiogenesis

\begin{tabular}{lccc}
\hline \multirow{2}{*}{ Treatment Group } & \multirow{2}{*}{ N } & \multicolumn{2}{c}{ Angiogenesis } \\
\cline { 3 - 4 } & & Mean & SD \\
\hline Control & 10 & 12.8000 & 1.31656 \\
$\mathrm{Ca}(\mathrm{OH})_{2}$ & 10 & 14.7000 & 1.88856 \\
$\mathrm{Ca}(\mathrm{OH})_{2}+$ Propolis & 10 & 18.6000 & 2.22111 \\
\hline
\end{tabular}

Tabel 4. Angiogenesis Tukey HSD Multiple Comparisons Test

\begin{tabular}{lccc}
\hline $\begin{array}{l}\text { Treatment } \\
\text { Group }\end{array}$ & Control & $\mathrm{Ca}(\mathrm{OH})_{2}$ & $\begin{array}{c}\mathrm{Ca}(\mathrm{OH})_{2}^{+} \\
\text {Propolis }\end{array}$ \\
\hline Control & 0.073 & $0.000^{*}$ \\
$\mathrm{Ca}(\mathrm{OH})_{2}$ & & $0.000^{*}$ \\
$\mathrm{Ca}(\mathrm{OH})_{2}+$ & & \\
Propolis & & & \\
\hline
\end{tabular}
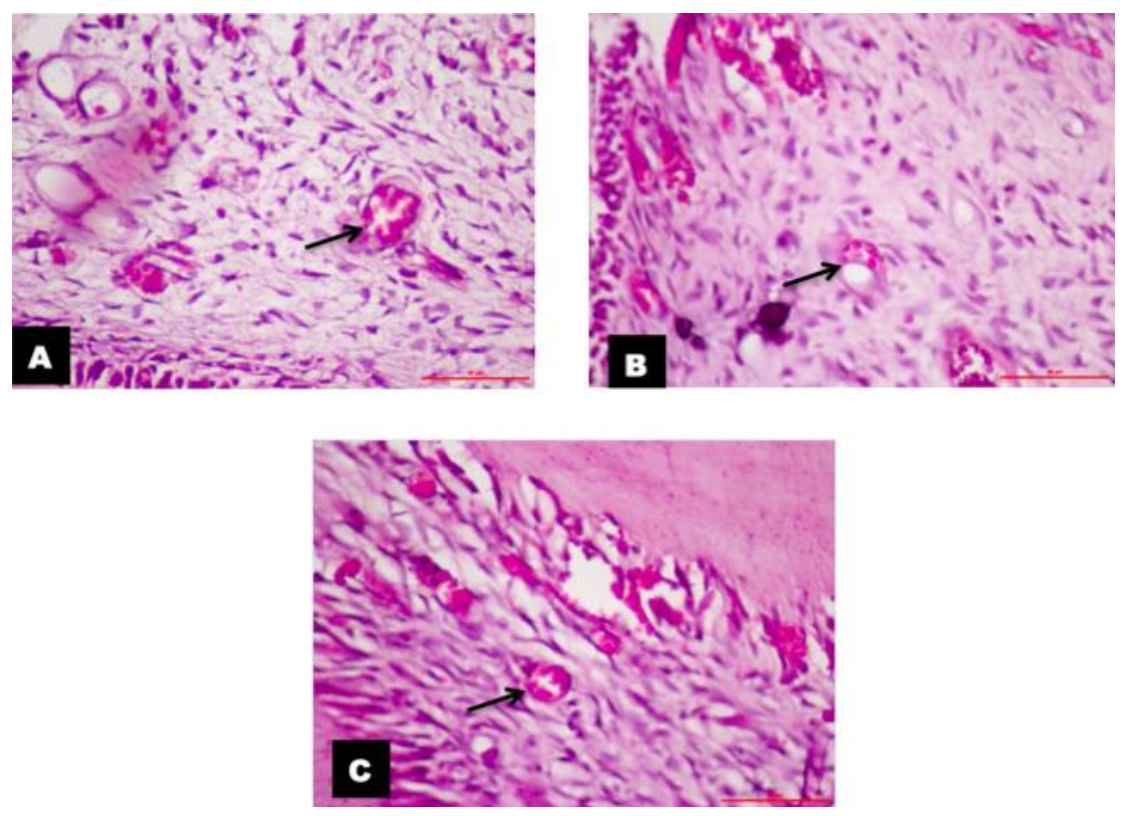

Figure 1. Description of fibroblast cells HPA in M1 dental pulp with a microscope in 400x magnification of dental pulp in group (A) control, (B) $\mathrm{Ca}(\mathrm{OH})_{2}$ and group (C) $\mathrm{Ca}(\mathrm{OH})_{2}+$ Propolis. Arrows point to fibroblast cells with HE painted 400x magnification
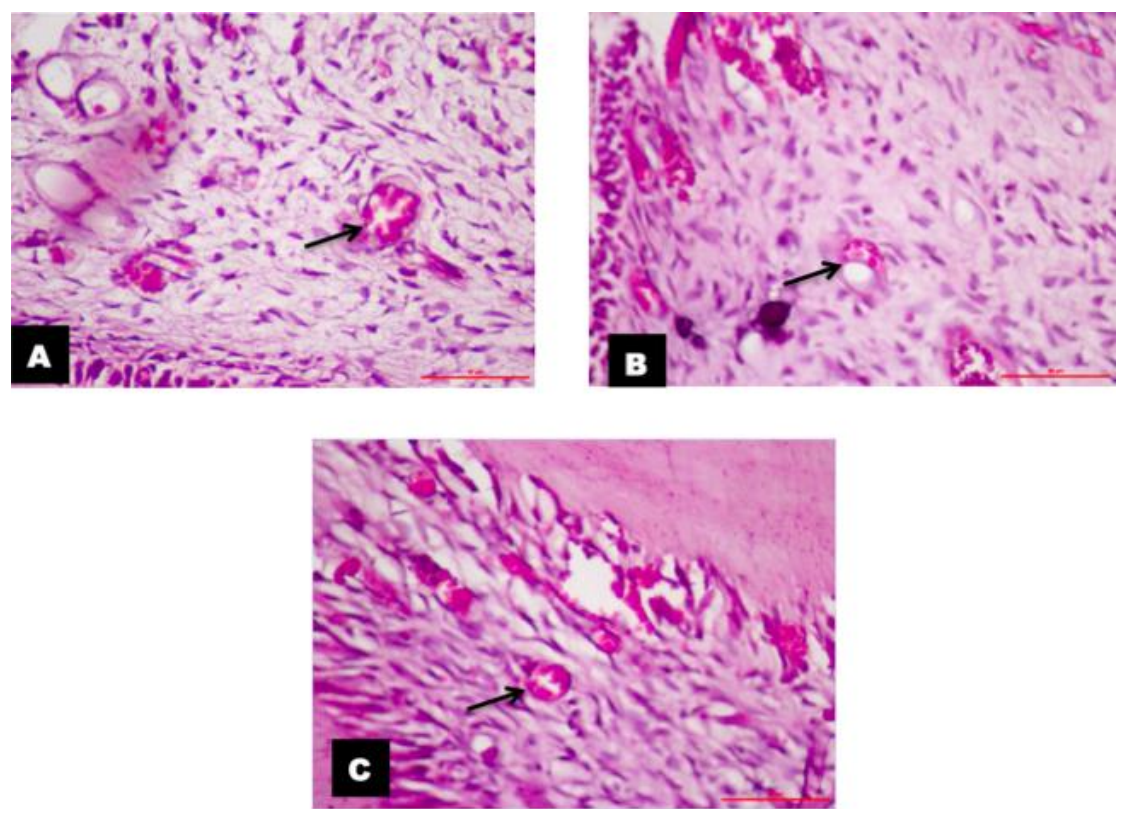

Figure 2. Description of angiogenesis HPA in M1 dental pulp with a microscope in 400x magnification of dental pulp in group (A) control, (B) $\mathrm{Ca}(\mathrm{OH})_{2}$ and group $(\mathrm{C}) \mathrm{Ca}(\mathrm{OH})_{2}+$ Propolis. Arrows point to angiogenesis with HE painted 400x magnification 
significant differences between treatment groups. The control group had significant differences with the $\mathrm{Ca}(\mathrm{OH})_{2}$ group and the $\mathrm{Ca}(\mathrm{OH})_{2}+$ propolis group, as well as the $\mathrm{Ca}(\mathrm{OH})_{2}$ and $\mathrm{Ca}(\mathrm{OH})_{2}+$ propolis groups as indicated by the significance values obtained between the treatment groups $<0.05$.

Based on anatomic histopathology (HPA) observations, the calculation of the amount of angiogenesis with the mean and standard deviation of the control group, the first treatment by giving $\mathrm{Ca}(\mathrm{OH})_{2}$-aquadest, and the second treatment by giving $\mathrm{Ca}(\mathrm{OH})_{2}$-propolis in Table 3 .

It can be seen through Table 3 the average number of angiogenesis of the three treatment groups. In the control group, the $\mathrm{Ca}(\mathrm{OH})_{2}$ group and the $\mathrm{Ca}(\mathrm{OH})_{2}+$ Propolis group, all three experienced an increase. Histopathological anatomy (HPA) picture of angiogenesis with 400x magnification in the pulp perforation of wistar rats can be seen in Figure 2.

The results of normality and homogeneity tests indicate that the data are normally distributed and homogeneous so that they meet the requirements for parametric tests using one way ANOVA test. One way ANOVA test results showed that there were significant differences between groups ( $p$ $<0.05)$.

Tukey HSD test was conducted to determine significant differences between groups. Table 4 shows that the control group did not have a significant difference with the $\mathrm{Ca}(\mathrm{OH})_{2}$ group as indicated by a significance value of 0.073 because $\mathrm{p}<0.05$. The control group and the $\mathrm{Ca}(\mathrm{OH})_{2}+$ propolis group had a significant difference as indicated by the significance value of $0,000(\mathrm{p}<0.05)$. The $\mathrm{Ca}(\mathrm{OH})_{2}$ group and the second treatment group $\mathrm{Ca}(\mathrm{OH})_{2}+$ propolis had a significant difference as indicated by a significance value of $0,000(\mathrm{p}<0.05)$.

\section{DISCUSSION}

Based on the results of the study there was a significant difference between the number of fibroblast cells in the control group, the treatment group with calcium hydroxide, the treatment group with a combination of calcium hydroxide and propolis based on the Krusskal Wallis test with $\mathrm{p}=0.000$ (sig $<0.05)$ indicating that there were differences between the study groups. In the Post Hoc Tukey HSD test, $p<0.05$ showed that there were significant differences between all study groups. An increased number of fibroblasts indicates a faster inflammatory process that affects the acceleration of wound healing

Based on the results of the study there was a significant difference between the amount of the control group angiogenesis and the treatment group with calcium hydroxide, the treatment group with a combination of calcium hydroxide and propolis based on the results of the One Way ANOVA test with $\mathrm{p}=0.000(\operatorname{sig}<0.05)$ showed that there were differences between the study groups. In the Post Hoc Tukey HSD test the results showed that the calcium hydroxide group had a significant difference with the $\mathrm{CaOH} 2$ group. An increasing number of angiogenesis indicates a faster inflammatory process which affects the acceleration of wound healing.

In the control group showed the lowest results both in fibroblast cells and angiogenesis compared with the treatment group with calcium hydroxide and the treatment group with a combination of calcium hydroxide-propolis because in the control group an inflammatory response occurred without the influence of certain substances. Odontoblast cells will be damaged when the preparation is done until perforation. This will result in irritant excitement or tissue injury will trigger the release of inflammatory mediators. In the lesion control group that occurs in the pulp it is only cursed using cention which is a resin-based alkaline material with a basic $\mathrm{pH}$ and its content, namely dimethacrylate which has irritant properties so that it can cause an inflammatory reaction ${ }^{7}$. Unlike the administration of calcium hydroxide-aquadest, although it also has a basic $\mathrm{pH}$ and causes the formation of a necrotic layer, calcium hydroxide-aquadest still has a role in reducing the inflammatory reaction in the pulp by forming dentin bridges that aim to accelerate healing.

In the group with administration of calcium hydroxideaquadest pulp tissue will experience irritation caused by high $\mathrm{pH}$ levels and accompanied by acute inflammation of the underlying tissue ${ }^{8,9}$. Calcium hydroxide is applied directly to the exposed pulp, after application necrosis will arise from adjacent and inflamed pulp tissue. Formation of a dentin bridge occurs at the confluence of necrotic tissue and inflamed vital tissue. Under the area of necrosis, the pulp tissue cells that underlie differentiation become odontoblast like cells and form a dentinal matrix ${ }^{10,11}$. Another thing is the combination of calcium hydroxide-propolis, in addition to the content of flavonoids and CAPE which works as an anti-inflammatory, the combination of calcium hydroxidepropolis is also neutral because calcium hydroxide with alkali nature is physically bound to alkali with propolis which is acidic with hydrogen and Van Der bond Waals thus has a $\mathrm{pH}$ of 7 or neutral which also plays a role in reducing the degree of inflammation.

In the treatment group with a combination of calcium hydroxide-propolis showed the highest significant results compared to the treatment group with calcium hydroxide and the control group because in the group given calcium hydroxide propolis combination there is propolis which has anti-inflammatory properties due to the main content in propolis namely CAPE and flavonoids can inhibit the nuclear factor kappa B (NF-kB) pathway which plays a role in inflammatory reactions and the release of proinflammatory cytokines (IL-1, IL-6, IL-8 and TNF- $\alpha$ ) thus affecting the activity of inflammatory cells by inhibiting neutrophil cell chemotaxis and vascular permeability ${ }^{12}$. Obstacles in neutrophil chemotaxis to the lesion area cause the number to decrease so that it stimulates the activation of macrophages and the number of macrophages will increase, the number of macrophages that increases will increase the growth factor secretion namely FGF and VEGF. Where these factors will stimulate the proliferation and migration of 
new cells to the injured area. FGF itself is the most important growth factor to help produce new fibroblasts ${ }^{13}$. Stimulated VEGF will stimulate the process of angiogenesis in tissues, where several phases such as vasodilation, degradation of the basal membrane, migration of endothelial cells, and proliferation of endothelial cells occur ${ }^{14}$. In the combination of calcium hydroxide and propolis extract, TGF $\beta$ increases. The function of TGF $\beta$ is to increase the activity of pulp cell proliferation and develop to form young fibroblasts. Young fibroblasts will differentiate to form odontoblasts like cells and increase expression of type 1 collagen to replace damaged odontoblasts ${ }^{15}$.

\section{REFERENCES}

1. Mikail, B., \& Candra, A. (2011, September). 90 persen anak SD di Bangka sakit gigi. Oktober 4,2011.

2. Harty, Ogston Robia. 2012. Kamus Kedokteran Gigi. Alih bahasa, Narlan S. Jakarta: EGC

3. Sabir, A., Mooduto, L., Kaelan, C., \& Horax, S. (2017). Impact of the use of Ethanolic Extract of Propolis, Flavonoid and Non-Flavonoid Propolis for Direct Pulp Capping in Collagen Type I Density. Brazilian Journal of Oral Sciences, 15(4), 264.

4. Brizuela, C., Ormeno, A., Cabrera, C., Cabezas, R., Silva, C., Ramiez, Mercade, M. 2017. Direct Pulp Capping with Calcium Hydroxide, Mineral Trioxide Aggregate, and Biodentine in Permanent Young Teeth with Caries: A Randomized Clinical Trial.Dental School, University de Los Andes, Santiago, Chile.

5. Djurica G, Danilovic V, Krsljak E. The effect of caffeic acid phenethyl ester on healing capacity and repair of the dentinpulp complex in vivo study: ActaVeterinaria (Beograd). 2008; 58(1):99-108.

6. Rajoo, M., Paroli, A., Pau, A,.Amalraj, FB. 2014. The Role of propolis in Inflammation and OrofacialPain : Annual Research \& Review in Biology 4(4):651-664,2014 Science Domain International www.sciencedomain.org.

7. Todd JC. 2016. Cention N-Scientific Documentation. Ivoclar vivadent. pp:7-18.

8. Baranwal, R., Singh, BD., Dubey, A., Avinash, A. 2016. Review Article Calcium Hydroxide in Dentistry. Chettinad Health City Medical Journal India 5(1): 30 - 33.

9. Mustafa, M., Saujanya, KP., Jain, D., Shetty, S., Arun, A., Uppin, L., Kadri, M., 2012. Role of Calcium Hydroxide in Endodontics: A Review. 1(1):66-67.

10. (Desai \& Chandler, 2009

11. Mohammadi Z \& Dummer PMH. Properties and Applications of Calcium Hydroxide in Endodontics and Dental Traumatology. International Endodontic J. 2011;44(8): 697730.

12. Freires, I., de Alencar, S. and Rosalen, P. (2016). A pharmacological perspective on the use of Brazilian Red Propolis and its isolated compounds against human diseases. European Journal of Medicinal Chemistry, 110, pp.267-279.

13. Kondo, Toshikazu dan Ishida Y. 2010. Molecular Pathology of Wound Healing. Forensic Science International 203: 9398

14. Scardina GA, Carini F, Noto P, Messina. 2013. Microcirculation in the Healing of Surgical Wounds in the Oral Cavity. Int. J. Oral Maxillofac. Surg; 42: 31- 35

15. Lucchini M, 2002, 'TGF Beta Signaling and Stimulating of Osteoadherin in Human Odontoblasts in Vitro', Connect Tissue Res. 43:345-353. 